\title{
A 2D hydrodynamic-sedimentological model for gravel-bed rivers. Part l: theory and validation
}

\author{
Gabriel Kaless, ${ }^{1}$ Mario A. Lenzi, ${ }^{1}$ Luca Mao${ }^{2}$ \\ ${ }^{1}$ Dipartimento Territorio e Sistemi Agroforestali, Università di Padova, Italy; ${ }^{2}$ Departamento de \\ Ecosistemas y Medio Ambiente, Pontificia Universidad Católica de Chile, Santiago, Chile
}

\begin{abstract}
This paper presents a novel 2D-depth average model especially developed for gravel-bed rivers, named Lican-Leufú (Lican=pebble and Leufu=river, in Mapuche's language, the native inhabitants of Central Patagonia, Argentina). The model consists of three components: a hydrodynamic, a sedimentological, and a morphological model. The flow of water is described by the depth-averaged Reynolds equations for unsteady, free-surface, shallow water flows. It includes the standard k-e model for turbulence closure. Sediment transport can be divided in different size classes (sand-gravel mixture) and the equilibrium approach is used for Exner's equation. The amour layer is also
\end{abstract}

Correspondence: Gabriel Kaless, TeSAF, Facoltà di Agraria, Università degli Studi di Padova, Via dell'Università 16, 35020 Legnaro (PD), Italy.

Tel. +39.049 .8272675 - Fax. +39.049 .8272686 .

E-mail: gabriel.kaless@unipd.it

Key words: gravel-bed rivers, 2D-depth-average model, hydrodynamic-sedimentological model, bed load, armour layer, bed evolution.

Acknowledgements: this research has been carried out within the frame of the UNIPD Project "CARIPARO-Linking geomorphological processes and vegetation dynamics in gravel bed rivers" and the UNIPD Strategic Project GEORISKS, Research Unit TeSAF Department. Part of this research was also founded by both, the SedAlp Project: Sediment Management in Alpine Basins: integrating sediment continuum, risk mitigation and hydropower, 83-4-3-AT, in the framework of the European Territorial Cooperation Programme Alpine Space 2007-2013, and the PRIN20104ALME4ITSedErosion: "National network for monitoring, modelling and sustainable management of erosion processes in agricultural land and hilly-mountainous area". We are very grateful to Robert Bernard for providing useful suggestions while developing the hydrodynamic model.

Contributions: the authors contributed equally.

Conflict of interests: the authors declare no potential conflict of interests.

Funding: the laboratory experiments were supported by a Marie Curie Intra European Fellowship (219294, FLOODSETS) within the 7th European Community Framework Program while Luca Mao was based at the Department of Geography of the University of Hull (UK).

(C) Copyright G. Kaless et al., 2013

Licensee PAGEPress, Italy

Journal of Agricultural Engineering 2013; XLIV(s2):e21

doi:10.4081/jae.2013.s2.e21

This article is distributed under the terms of the Creative Commons Attribution Noncommercial License (by-nc 3.0) which permits any noncommercial use, distribution, and reproduction in any medium, provided the original author(s) and source are credited. included in the structure of the model and the surface grain size distribution is also allowed to evolve. The model simulates bank slides that enable channel widening. Models predictions were tested against a flume experiment where a static armour layer was developed under conditions of sediment starvations and general good agreements were found: the model predicted adequately the sediment transport, grain size of transported material, final armour grain size distribution and bed elevation.

\section{Introduction}

The observed shape of a river is the consequence of controlling processes such as the flow of water and sediments, and the forces of boundary conditions such as valley confinement and slope, vegetation, etc. The resulting river morphology is the complex result of the complex interactions between sediment transport, flow of water, and channel morphology. In the last years several models have been developed for explaining and predicting the shape of a river. These models constitute the everyday growing discipline of Computational Fluid Dynamics. Many models have been especially created for reproducing the complex flow in meandering rivers (Wu et al., 2000; Ferguson et al., 2003; Abad et al., 2008). The flow of water in meandering rivers is highly disturbed by channel sinuosity that induces secondary currents (Rozovskii, 1961). Sediment is transported both in suspension and as bed load and comprises fine sizes, i.e., sand. Moreover, bank failure models have to consider material cohesion due to the presence of silt and clay (Darby et al., 2002).

Gravel-bed rivers are usually located within mountain landscapes. They present several features that differentiate them from meandering rivers: both bed and banks are composed of non-cohesive material (mixture of sand, gravel and cobbles, although a "virtual" cohesion can be provided by vegetation roots), the aspect ratio(width/depth) is higher because channels are wider and shallower; bed load sediment transport is responsible of channel form been material in suspension negligible for channel change (Leopold, 1992), and the bed is usually armoured, which regulates the interaction between bed surface and sediment transport. These features impose new and different challenges for modelling. Also, the last years have witnesses the production of numerical models that consider some of the aforementioned features: Nataga et al. (2000) developed a depth-average shallow water model including a sediment transport model (with only one grain size) and a bank failure model for gravel-bed rivers. Later, Jang and Shimizu (2005) and Garcia-Martinez et al. (2005) developed models for wide channels using the Meyer-Peter and Müller sediment transport formula for uniform material. Finally, Li and Millar (2007) extended the Mike 21C model implementing Parker's (1990) sediment transport model for mixtures.

The main objective of this paper is to present a novel numerical model especially design for assessing morphological changes in grav- 
el-bed rivers, called Lican-Leufú 2D model (Lican and Leufu are two words two words of the Mapuche language, the native inhabitants of Central Patagonia, Argentina; the words indicate the two key aspects of the new model: the flow of water, Leufu = river, and the processes related with gravel transport, Lican = pebble). The model considers the presence of an armour layer, the transport of sand-gravel mixtures, and bank erosion processes.

\section{The 2D hydrodynamic and sedimentological model}

\section{Hydrodynamic model}

The governing equations are composed of the depth-averaged versions of mass balance and momentum balance for shallow water, unsteady flows:

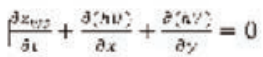

$$
\begin{aligned}
& \frac{\partial y}{j t}+U \frac{\partial y}{\partial x}+V \frac{\partial y}{\partial v}=-g \frac{\partial z_{W z}}{\partial x}+T_{x}-C h^{-1} U|U| \\
& \frac{\partial V}{\partial t}+U \frac{\partial V}{\partial x}+V \frac{\partial c}{\partial y}=-g \frac{\partial u_{s s}}{\partial y}+7 ;-C h^{-1} V|U|
\end{aligned}
$$

where in $z_{w s}$ is the water surface elevation, $\mathrm{h}$ is the flow depth, $\mathrm{U}$ and $\mathrm{V}$ are the depth-average quantities of local velocities, $|\mathrm{U}|$ is the modulus of the depth-averaged velocity vector, $\mathrm{T}$ is the force due to viscous effects, and C, a friction factor. This coefficient is related to the bed roughness using Keulegan's (1938) equation and Kamphius's (1974) experimental results supported by field measurements (Kaless, 2013):

$$
C^{-2}=2.5 i n\left(11 \frac{n}{2 \omega_{n}}\right)
$$

Viscous forces are the result of turbulent flow. Viscous force T represents the turbulence effects on the mean flow. Bernard (1993) proposed the following expressions:

$$
\begin{aligned}
& T_{x}=\partial^{-1} v_{i} V \cdot(h v U)+2 \frac{\partial y}{\partial x} \frac{\partial u}{\partial x}+\frac{\partial v_{z}}{\partial y}\left(\frac{\partial y}{\partial y}+\frac{\partial z}{\partial x}\right)
\end{aligned}
$$

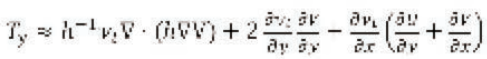

where $v_{t}$ represents the depth-averaged kinematic eddy viscosity. The standard k-e model is used for the turbulence closure. The kinematic eddy viscosity is evaluated by an empirical formula in terms of the turbulent kinetic energy $(\mathrm{k})$ and the energy dissipation rate $(\varepsilon)$. Both variables, $\mathrm{k}$ and $\mathrm{e}$, have to be found solving two transport-type partial differential equations (for a thorough exposition see Rodi, 1993, and Bernard, 1993).

Finally, sidewall effects are considered negligible in shallow water flows which are usually observed in gravel-bed rivers.

\section{Sediment transport model}

Sediment transport is modelled assuming local equilibrium conditions (Wu, 2007), and using the Exner's equation which relates spatial changes in sediment transport with temporal variation of bed elevation. It is expressed in the following way:

$$
\left(1-\lambda_{i}\right) \frac{\partial x_{i}}{\partial t}=-\sum_{i} \nabla \cdot q_{i:}
$$

where $\lambda_{\mathrm{p}}$ is the bed material porosity, $\mathrm{z}_{\mathrm{b}}$ is the bed elevation and $\mathrm{q}_{\mathrm{k}}$ is the sediment transport vector for the $\mathrm{k}^{\text {th }}$ grain size class, which is eval- uated with a sediment transport model. The sum on the right side indicates that the divergence must be evaluated for all the grain size classes. The temporal evolution of the surface grain size distribution is described using the active layer approach (Hirano, 1971; Parker and Southerland, 1990). The mass balance is applied to analyze interactions between sediment transport, active layer and sublayer:

$$
\frac{\partial\left(L_{L} F_{k}\right)}{\partial t}=\frac{\nabla \cdot q_{k}}{\left(1-\lambda_{j}\right)}+f_{i K}\left(\frac{\partial L_{\mathrm{LL}}}{\partial t}-\frac{\partial z_{\mathrm{E}}}{\partial t}\right)
$$

where in $L_{a}$ is the height of the active layer, $F_{k}$ and $f_{\mathrm{lk}}$ are the surface and interface exchange grain fractions (for the $\mathrm{k}^{\text {th }}$ grain size class), respectively. The active layer has a height of the same order that the largest particles: $L_{a}=2$ d.The interface grain size distribution $f_{\mathrm{lk}}$ depends on whether the bed is degrading or aggrading. When the bed degrades $f_{\mathrm{lk}}$ is equal to the substrate grain size distribution. On the contrary, when bed aggrades a mixture between the bed load and the active layer material is adopted (Parker et al., 2006). The evaluation of the sediment transport vector $\mathrm{q}_{\mathrm{k}}$ requires the definition of its modulus (transport intensity) and its direction, i.e., the components along the $\mathrm{x}$ and $y$ axes. The bulk transport of the $\mathrm{k}^{\text {th }}$ grain size class is calculated using the Wilcock and Crowe's (2003). Bed load direction is evaluated according to the near-bed flow direction and bed topography as well (see Parker, 2006). Sediment transport direction depends on the flow direction but is influence by gravity effects due to bed slope and grain size (for a thorough exposition see Kaless, 2013).

\section{Bank erosion model}

Sediment transport near the banks is expected to produce local erosion. This process increases the bank slope, and when this exceeds the response angle it collapses. The heuristic model proposed by Jang and Shimizu (2005) has been adopted for modelling the bank failure. When the slope exceeds the angle of repose (assumed to be $\phi=?$ ?, the dynamic Coulomb coefficient) a failure surface inclined at the angle of repose is extended up to the floodplain surface. All the sediment above the failure lines moves downslope to form a deposit with a linear upper surface. Furthermore, the new surface grain size distributions for deposited and eroded areas are evaluated considering a mixture between the previous surface layer and the substrate material (see Kaless, 2013 for further details).

\section{Boundary conditions}

The solution of the governing equations requires the specification of the boundary conditions and the initial condition. The boundary conditions consist of the specification of water and sediment fluxes and their distribution along the upstream cross section and water level at the downstream end, for which the normal flow is adopted. Flow through the lateral boundaries is not allowed. Because flow is unsteady, a specific treatment (drying/wetting processes) was considered for inner and lateral boundaries.

\section{Numerical methods}

A finite-volume discretization scheme with a curvilinear boundaryfitted grid was adopted. The location of dependent variables is specified according to a staggered grid: fluxes $\left(Q_{u}\right.$ and $\left.Q_{v}\right)$ are calculated at facecentre, and scalar variables (water elevation, turbulent kinetic energy $\mathrm{k}$, dissipation rate $\varepsilon$, sediment transport, bed elevation and grain size distributions) are calculated at cell-centre. The cell-centred depth-averaged velocities $\mathrm{U}$ and $\mathrm{V}$ are computed from $Q_{u}$ and $Q_{v}$ only when they are needed, for instance, to compute the viscous, friction forces and bottom shear stress.

The governing equations are transformed from Cartesian ( $\mathrm{x}, \mathrm{y})$ coordinates to curvilinear coordinates $\xi=\xi(\mathrm{x}, \mathrm{y})$ and $\eta=\eta(\mathrm{x}, \mathrm{y})$. Each cell 
is composed of four nodes that can be placed arbitrarily, so spacing Dx and Dy are variable. Conversely, in the computational domain the spacing is constant: $\Delta \xi=1$ and $\Delta \eta=1$. Using the coordinate transformation $\xi=\xi(\mathrm{x}, \mathrm{y})$ and $\eta=\eta(\mathrm{x}, \mathrm{y})$, it is possible to obtain the corresponding expression for each differential operator in the governing equations (Bernard, 1993). Advection terms require specific numerical methods in order to avoid instabilities: a) the momentum equation is solved applying the MacCormack's predictor-corrector scheme, adapted from Bernard's (1993) for solving a free surface flow; b) the transport equations of the Standard k- $\varepsilon$ model are solved using the Euler (first order) upwind scheme; and c) the Exner equations (for bed elevation and grain size distribution) employ the Euler's scheme with the HLPA interpolation method for the divergence term (Zhu, 1991).

Flow and sediment transport calculations are decoupled because bed changes are very slow. First, the flow equations are solved considering a fixed bed, and then sediment transport is calculated considering water surface and discharge fixed (but water depth and mean velocity are adjusted considering bed elevation changes). For low-term simulations a tolerance is imposed for bed change and when this is exceeded, the hydraulic parameters are updated solving the flow equations. Instead, for a long-term simulation that normally spans several days, hydraulic parameters are hold fixed during the time step (normally assumed to be one day).

Because flow is unsteady a criterion was established to assess when the flow has reached a steady condition. The hydrodynamic calculation stops when the difference between the discharge through all the cross sections and the incoming discharge is below a given tolerance.

\section{Validation against a flume experiment}

The model has been tested using the results from a flume experiment carried on to develop a static armour layer under conditions of sediment starvation. Four parameters were used for the comparison: load and grain size distribution of the outgoing sediment transport during the armouring process, and the final bed elevation and surface grain size distribution.

\section{Experimental settings}

The physical experiment was conducted at the laboratory of the University of Hull (U.K.), within the facilities of the Total Environmental Simulator. The flume was a $2 \mathrm{~m}$ wide and $11 \mathrm{~m}$ long with a longitudinal slope of $0.005 \mathrm{~m} \mathrm{~m}^{-1}$. At its downstream end, eight traps covering the whole flume width were used to collect the transported sediments. Traps were collected and emptied at variable intervals in order to derive bedload transport rates and grain size. The bulk gravelsand mixture had the following percentiles: $\mathrm{D}_{16}=4.1 \mathrm{~mm}, \mathrm{D}_{50}=6.4 \mathrm{~mm}$ and $D_{84}=13.1 \mathrm{~mm}$. At the beginning of the experiment sediments were screeded flat to the specified bed slope. Only one run was performed with a water discharge of $340 \mathrm{l} \mathrm{s}^{-1} \mathrm{~m}^{-1}$. Pressure transducers were placed beneath the sediments along the channel centre for measuring the water surface elevation.

The experiment run until the outgoing sediment transport was 1\% the initial value. At this moment photographs of the bed surface were taken and after, the grid-by-number approach was used to evaluate the average surface grain size distribution. Bed elevations were also measured along the left wall of the flume.

\section{Numerical method settings}

Because there was no armour at the initial state the surface grain size distribution was assumed equal to the bulk sand-gravel mixture.
The initial water surface elevation was calibrated against measurements so as to assure similar hydrodynamic conditions in the flume and in the model. The porosity of the mixture was not measured. Instead it was calculated using an empirical formula proposed by $\mathrm{Wu}$ and Wang (2006), giving the value $\lambda_{p}=0.27$.

The boundary conditions assumed for the simulations are: a) Fixed downstream water surface elevation; b) Constant upstream incoming water discharge; c) Null sediment supply; and d) Fixed bed elevation at the downstream end. The model was run under the "low-term" configuration.

Several parameters were selected for analyzing the model sensibility (Table 1). They belong to three groups: a) the mesh density represented with the downstream spacing $(\Delta x)$, b) hydrodynamic parameters including the convergence tolerance $\left(\mathrm{Tol}_{0}\right)$ and the downstream water surface elevation $\left(\mathrm{H}_{\mathrm{dw}}\right)$; and $\mathrm{c}$ ) sedimentological parameters including the tolerance for bed elevation change $\left(\mathrm{Tol}_{\mathrm{z}}\right)$ and bed porosity $\left(\lambda_{p}\right)$.

\section{Results}

During the experiment, the bed experienced a degradation in its upstream end and a progressive bed surface coarsening. An erosion scour formed at the upstream end of the flume. Sediment transport rate reached the highest intensity at the beginning of the experiments (53 $\mathrm{gr} \mathrm{m}^{-1} \mathrm{~s}^{-1}$ ) and decreased quickly been below $1 \%$ of the initial rate after $45 \mathrm{hr}$.

Two indexes were used to summarize the model performance: abosolute difference (AD) employed for comparing predicted and observed bed elevations ( $z_{\text {pred }}$ and $z_{\text {obs }}$ respectively) and the absolute logarithmic ratio (ALR), in the case of discharges (q):

$$
\begin{aligned}
& A \nu=\frac{1}{n} \sum_{:=1}^{*}\left|z_{n r c c t, i}-z_{u b s, i}\right|
\end{aligned}
$$

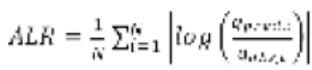

where in $\mathrm{N}$ is the number of observations. The entire numerical runs exhibit the exponential-type tendency observed in the experiment (Figure 2). The grid spacing affects little the predicted outgoing sediment flow, due to similar ALR values (Table 2). Also, low changes are observed when $\mathrm{Tol}_{Q}$ is relaxed (see runs 8,9 and 10 ). The model is quite

Table 1. Variation in selected parameters for model sensibility analysis: grid spacing in the downstream direction $(\nabla x)$ and across the flume $(\otimes y)$; downstream water depth $\left(\mathrm{H}_{\mathrm{dw}}\right)$; tolerance for model convergence $\left(\mathrm{Tol}_{\mathrm{Q}}\right)$; tolerance for bed elevation change $\left(\mathrm{Tol}_{\mathrm{z}}\right)$ and bed material porosity $\left(\lambda_{\mathrm{p}}\right)$.

\begin{tabular}{lllllll} 
Run & $\Delta x$ & $\Delta y$ & $H_{d w}$ & Tole & Tol & $\lambda_{\mathrm{p}}$ \\
W1 & 0.500 & 0.125 & 0.195 & $1 \%$ & $2 \%$ & 0.27 \\
W2 & 0.250 & 0.125 & 0.190 & $1 \%$ & $2 \%$ & 0.27 \\
\hline W3 & 0.125 & 0.125 & 0.185 & $1 \%$ & $2 \%$ & 0.27 \\
W4 & 0.125 & 0.125 & 0.185 & $1 \%$ & $5 \%$ & 0.27 \\
\hline W5 & 0.125 & 0.125 & 0.185 & $1 \%$ & $10 \%$ & 0.27 \\
W6 & 0.250 & 0.125 & 0.200 & $1 \%$ & $2 \%$ & 0.27 \\
\hline W7 & 0.250 & 0.125 & 0.210 & $1 \%$ & $2 \%$ & 0.27 \\
W8 & 0.125 & 0.125 & 0.185 & $1 \%$ & $2 \%$ & 0.34 \\
\hline W9 & 0.250 & 0.125 & 0.190 & $2 \%$ & $2 \%$ & 0.27 \\
W10 & 0.250 & 0.125 & 0.190 & $5 \%$ & $2 \%$ & 0.27 \\
\hline
\end{tabular}


sensitive to changes in the downstream water surface elevation (runs 2, 6 and 7): when the depth is increased the initial transport rate decreases significantly as evident from the reduction in the relative peak discharge (Table 2). The best agreement corresponds to calibrated boundary condition (Run 2). Finally, the change in $\mathrm{Tol}_{\mathrm{Z}}$ (runs 3, 4 and 5) did not affect the exiting sediment transport.

With regards to the grain size distribution (GSD) of outgoing bed load (Figure 3), all the runs predicted the same distribution. The predicted GSD approximated very well the observed GSD for the lower percentiles $\left(\mathrm{D}_{16}, \mathrm{D}_{50}\right.$, Table 3$)$, i.e., the predicted median diameter was very near the observed mean value. There is a clear discrepancy for the coarser fractions: the predicted percentile $84 \%$ is somewhat lower than observations.

In general, bed was incised not uniformly across the flume (Figure 3 ), with the deepest sector in the channel centre and almost no erosion at the sidewalls. Erosion was higher at the downstream end in contradiction with observations. Changing the grid spacing, porosity or tolerance $\mathrm{Tol}_{z}$ produced only slight changes. On the contrary, the model was more sensible to changes in boundary conditions. The rise in the downstream water surface elevation $(\mathrm{H}=0.19 ; 0.20$ and $0.21 \mathrm{~m})$ reduced the amount of erosion and the final bed profile was progressively at higher levels (note that $\mathrm{AD}$ decreases in Table 2 for runs 2, 6 and 7). The model was also sensible to changes in the discharge convergence tolerance ( $\mathrm{Tol}_{0}$, see AD change in runs 8,9 and 10 , in Table 2 ).

Table 3 also includes representative diameter for the final surface material. With regards to measurements, Figure 5 shows the mean distribution from 10 photographs and it also includes enveloping maximum and minimum curves. It is noted that the predicted grain size distribution is very similar to that measured and is within the aforementioned band. The predicted $D_{50}$ was7.5 mm while the predicted was $D_{50}$ $=8.1 \mathrm{~mm}$.

\section{Discussion}

Lican-Leufú predictions have been tested against a flume experiment that involves a change in bed elevation, surface grain size distribution, flow hydraulics and sediment transport as well. Because all these factors are tightly related, the experiment constitutes a good opportunity to assess the model capabilities.

The model was very sensitive to boundary conditions. A slight change of the downstream water surface elevation had an evident effect on the transported sediment flux and final bed elevation because the higher water surface reduced flow velocity and bottom shear stress. Then, as there was a no-linear relation between shear stress and sediment transport, a small reduction in $\tau$ was amplified into the transport rate. The higher the water surface elevation, the lower the shear stress, sediment transport and hence, the final bed elevation was higher.

Previous researches have shown that armouring development occurs into two phases: a first phase were bed degrades and then a second phase where the surface coarsens due to selective transport of fine sediments at flows below the threshold for entrainment of larger grain sizes, such that the bed surface is winnowed of the most easily moved fine sediment (Church et al., 1998; Wilcock et al., 2001; Mao et al., 2011). When the static armour layer has developed sediment transport vanishes.

The application of the model shows that during the first phase sediment transport decreases as bed slope reduces (i.e., it is entirely governed by hydraulics). The second phase was also present in the experiment: although the final surface grain size distribution was only slightly coarser than the initial one, an incipient static armour developed. The measured absolute degree of armouring was $\mathrm{D}_{50} / \mathrm{D}_{50 \mathrm{ss}}=1.26$, while the predicted one was 1.17. This indicates that selective transport took place in the flume. In order to verify this affirmation, fractional rates were calculated using sediment transport rates at the beginning and the end of the experiment. For the initial state, the initial bulk grain size distribution was considered, while the final surface grain size distribution was considered for the final fractional rate. Resulting curves (not showed) showed that at the beginning of the experiment, when there was no armour layer, all the grain fractions were transported (full transport). On the contrary, by the end of the experiment partial transport occurred. Coarse material remained in the bed while fine grains were winnowed.

Table 2. Comparison of model predictions against observations. Sediment transport is compared using the absolute logarithmic ratio (ALR), while med bed elevations are compared with the absolute difference index $(\mathrm{AD})$.

Run Sediment Relative Mean bed trans-

\begin{tabular}{llll} 
W1 & 0.25 & 0.62 & 0.031 \\
W2 & 0.26 & 0.73 & 0.034 \\
\hline W3 & 0.27 & 0.73 & 0.036 \\
W4 & 0.28 & 0.81 & 0.036 \\
\hline W5 & 0.28 & 0.76 & 0.038 \\
W6 & 0.23 & 0.52 & 0.027 \\
\hline W7 & 0.26 & 0.35 & 0.021 \\
W8 & 0.24 & 0.71 & 0.037 \\
\hline W9 & 0.24 & 0.78 & 0.033 \\
W10 & 0.26 & 0.59 & 0.032 \\
\hline
\end{tabular}

Table 3. Comparison between predicted and observed grain size distributions (GDS) of outlet sediment transport and final surface material.

\begin{tabular}{llccc} 
D16 (mm) & 3.0 & 3.6 & 4.5 & 4.1 \\
D50 (mm) & 5.4 & 5.6 & 7.5 & 8.1 \\
\hline D84 (mm) & 8.0 & 10.3 & 16.1 & 17.7 \\
\hline
\end{tabular}

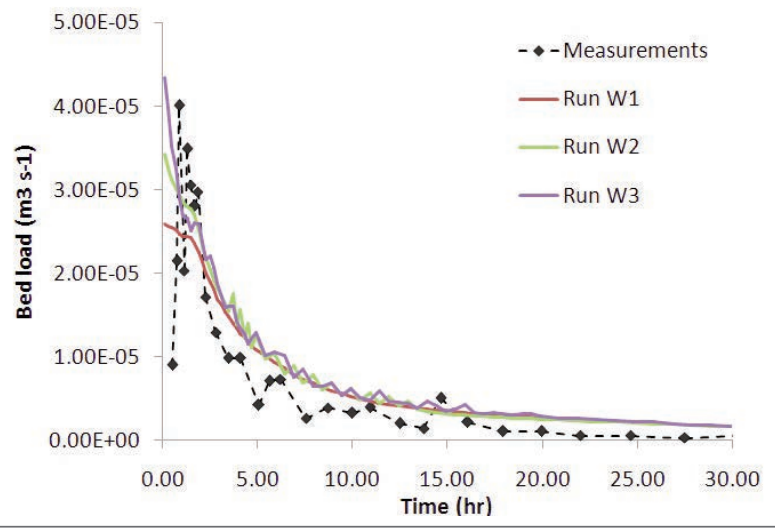

Figure 2. Comparison of predicted and observed outgoing sediment transport. Different curves evidence the sensibility of the mode predictions to changes in grid spacing (runs 1, 2, 3, see Table 1). 


\section{Conclusions}

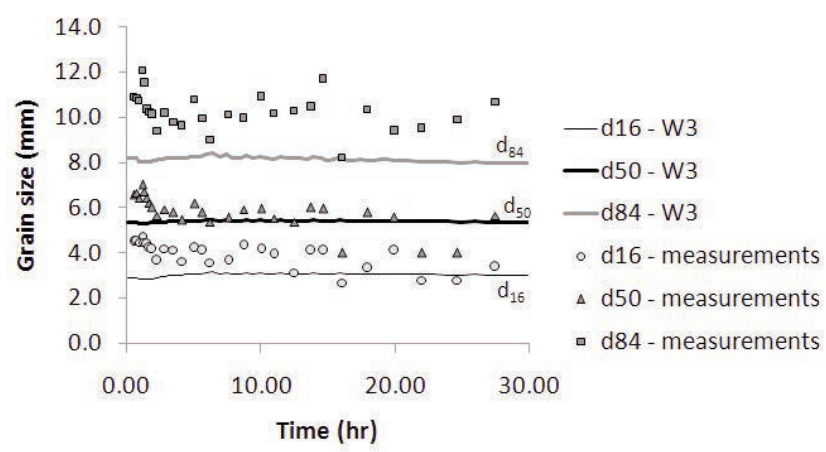

Figure 3. Comparison between predicted and observed bed load grain size. Because all the runs have almost identical values, only results from run 3 are shown.

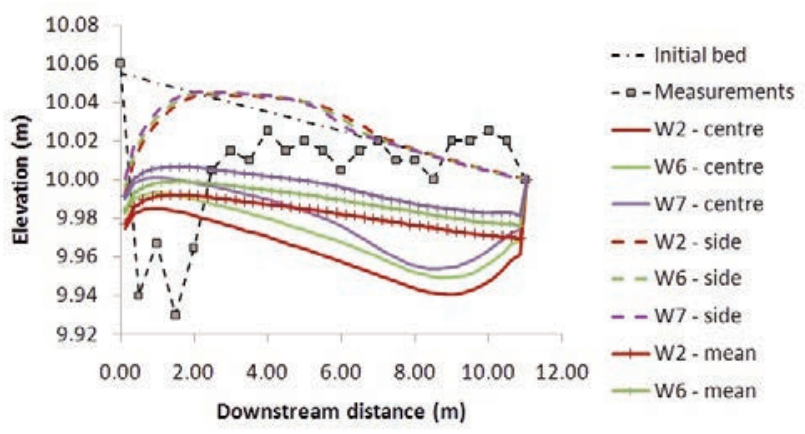

Figure 4. Comparison between observation and prediction for the final bed elevation. Model sensibility has been assessed by changing the downstream water surface elevation (runs 2, 6 and 7, see Table 1 ).

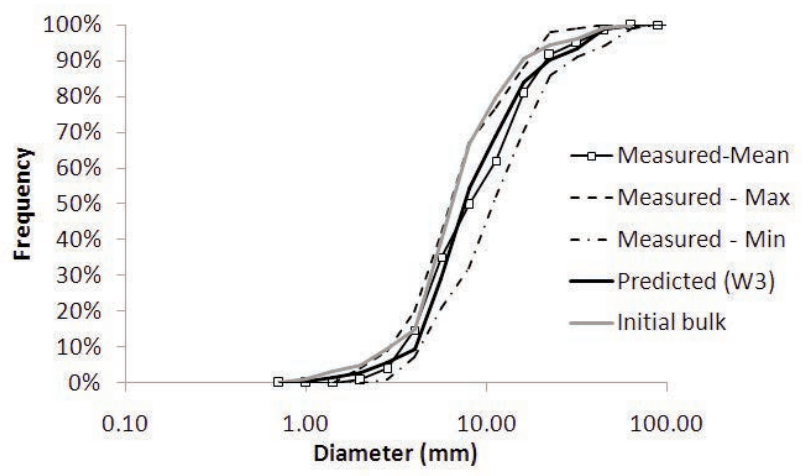

Figure 5. Comparison between predicted and observed final grain size distributions of surface material. Because the observed curve is the result of the analysis of 10 photographs a mean curve is exposed and enveloping curves are also provided.
Overall, Lican-Leufú model proved to perform remarkably well in reproducing the experimental runs because: a) the outgoing sediment flux was correctly predicted in terms of transport rate and calibre; b) final mean bed elevation was very similar to that measured (considering that only near sidewalls elevations were available); and c) the predicted surface grain size distribution was in agreement with observations.

Previous researchers have identified two phases during the development of static armour layers. The application of Lican-Leufú indicates that the interaction between hydraulics and bed degrading was the main factor driving sediment transport and full transport prevailed in the initial phase of the experiment. By the end of the experiment, partial transport occurred due to bed coarsening, coarse material remain in the flume and fine sediments were winnowed.

\section{References}

Abad JD, Buscaglia G, Garcia MH. 2D stream hydrodynamic, sediment transport and bed morphology model for engineering applications. Hydrol Process 2008; 22: 1443-59.

Bernard RS. Numerical model for depth-averaged incompressible flow. US Army Corp of Engineers, Waterways Experimental Station, Technical Report REMR-HY-11, 1993.

Church M, Hassan MA, Wolcott JF. Stabilizing self-organized structures in gravel-bed stream channels: Field and experimental observations. Water Resour Res 1998; 34: 3169-79.

Darby SE, Alabyan AD, Van de Wiel MJ. Numerical simulation of bank erosion and channel migration in meandering rivers. Water Resour Res 2002; 38, doi:10.1029/2001WR000602.

Garcia-Martinez R, Espinoza R, Valera E, Gonzalez G. An explicit twodimensional finite element model to simulate short- and long-term bed evolution in alluvial rivers. J Hydraul Res 2005; 44, 755-66.

Ferguson RI, Parsons DR, Lane SN, Hardy RJ. Flow in meander bends with recirculation at the inner bank. Water Resour Res 2003; 39, 1322, DOI:10.1029/2003WR001965.

Hirano M. River bed degradation with armouring. Proceedings of the Japan Society of Civil Engineering 1971, 55-65.

Jang CL, Shimizu Y. Numerical simulation of relative wide, shallow channels with erodible banks, J Hydraul Eng 2005; 131: 565-75.

Kaless G. Stability analysis of gravel-bed rivers: Comparison between natural rivers and disturbed rivers due to human activities. $\mathrm{PhD}$ Diss., Università degli Studi di Padova, Italy, 2013.

Kamphuis JW. Determination of sand roughness for fixed beds. J Hydraul Res 1974; 12: 193-203.

Keulegan GH. Laws of turbulent flow in open channels, National Bureau of Standards Research Paper RP 1151, Washington D.C., 1938.

Leopold LB. Sediment size that determines channel morphology. In Billi P, Hey RD, Thorne CR, Tacconi P, eds. Dynamics of Gravel-bed Rivers. Chichester: John Wiley and Sons; 1992: 297-311.

Li SS, Millar RG. Simulating bed-load transport in a complex gravel-bed river. J Hydraul Eng 2007, 133, Doi:10.1061/(ASCE)0733 9429(2007)133:3(323).

Mao L, Cooper J, Frostick L. Grain size and topographical differences between static and mobile armour layers. Earth Surf Proc Land 2011, DOI:10.1002/esp.2156.

Nagata N, Hosoda T, Muramato Y. Numerical analysis of river channel processes with bank erosion. J Hydraul Eng 2000; 126: 243-52. 
Parker G. Surface-based bedload transport relation for gravel rivers, J Hydraul Res 1990, 28: 417-36.

Parker G. Transport of gravel and sediment mixtures. In: Garcia MH, ed. Sedimentation Engineering, Processes, measurements, modelling and practice; ASCE Manuals and Reports on Engineering Practice No. 110, ASCE 2006: 165-251.

Parker G, Sutherland AJ. Fluvial armor. J Hydraul Res 1990; 28: 529-44.

Parker G., Hassan M, Wilcock P. Adjustment of the bed surface size distribution of gravel-bed rivers in response to cycled hydrographs. In: Habersack H, Piegay H, Rinaldi M, eds. Gravel Bed Rivers 6: From process understanding to river restoration, Amsterdam, Elsevier Science 2006: 241-85.
Rodi W. Turbulent models and their applications in hydraulics, A stateof-the-art review, 3rd Edition. IAHR Monograph Series, New York ,Taylor \& Francis 1993.

Rozovskii IL. Flow of water in bends of open channels. Translated by Y. Prushansky, Jerusalem Program Sci. Translation, 1961.

Wilcock PR, Kenworthy ST, Crowe J. Experimental study of the transport of mixed sand and gravel. Water Resour Res 2001; 37, 3349-58.

Wilcock PR, Crowe JC. Surface-based transport model for mixed-size sediment, J Hydraul Eng 2003; 129: 120-8.

Wu W, Wang SSY. Formulas for sediment porosity and settling velocity. J Hydraul Eng 2006; 132: 858-62. 